\title{
Creating learning communities: three social software tools
}

\author{
Dr Amanda Tinker \\ University of Huddersfield, UK \\ Gillian Byrne \\ University of Huddersfield, UK \\ Christine Cattermole \\ University of Huddersfield, UK
}

\section{Introduction}

I have always imagined the information space as something to which everyone has immediate and intuitive access, and not just to browse, but to create. (Berners-Lee, 1999: 169)

Use of the web today, particularly amongst young people, is now more social and participative. Collectively known as Web 2.0, freely available tools have emerged that facilitate communication, user-generated content and social connectivity. Facebook and MySpace have become the most popular forms of this kind of online activity and networks are formed around all kind of interest and issues whether they are political, educational, professional or hobbies. In a recent survey of 500 students, $80 \%$ claimed that they regularly use social networking tools to communicate with peers (JISC, 2008). This pervasive use of Web 2.0 technology for everyday interaction has yet to see its potential fully recognised and integrated into Higher Education pedagogy. Despite $73 \%$ of students using such tools to 'discuss coursework' and $75 \%$ of these students recognising their value for enhancing learning, only $25 \%$ were encouraged to use such social software by academic staff (JISC, 2008). This raises the question as to whether Web 2.0 technology can promote social learning within educational contexts and how this might be realised in practice.

Mason and Rennie (2008) whilst pointing to the popularity amongst the student body of Web 2.0 technology acknowledge that making use of these tools educationally may not be 
without its issues. Many students may be quick adopters of this new technology, however, academics may not be so fast and trends may complicate institutional adoption of any one tool (Mason and Rennie, 2008). What is also worth considering is that not all of our students can be classed as Prensky's (2001: 1) 'digital natives' (Currant et. al., 2008).

However, the popularity of these tools and their pervasive nature within society makes them of interest to the educational community. Thus, in a bid to harness this creativity, energy and sociability, the Academic Skills Tutors (ASTs) at the University of Huddersfield have been exploring Web 2.0 technologies to investigate how such tools might enhance teaching and learning. This paper introduces practical examples of social software tools; how these are currently used to foster learning communities and promote academic development. Three distinct social software tools are discussed (del.icio.us, PBwiki and Ning), illustrating current use of these with students and their initial evaluation.

\section{Social bookmarking: collaborative resource sharing}

Web 2.0 software has opened up an opportunity for 'learning activities' that encourage students to become interactive with others (Dotsika and Patrick, 2006). Social bookmarking sites, such as del.icio.us (http://delicious.com/), allow the user to search and 'tag' suitable resources to add to a personal webpage which can be built up quickly and shared with others. However, where traditional forms of metadata use hierarchical structure, del.icio.us employs a '...controversial new form of metadata, the folksonomey' [tag], although users are reminded of 'previously deployed tags' to help them arrange the URLs in a suitable manner (Alexander 2006: 34). The increase of user contribution and 'engagement with content promotes a sense of community, empowerment and ownership' which not only increases the 'resource bank' but elevates student motivation (Boulos and Wheeler, 2007: 4). Bookmarks can be shared with colleagues and students but the uniqueness of this system is that anyone can access the bookmark from any computer, unlike the 'favourites' system currently used by many users. Del.icio.us allows the user to build up a collection of records that are available publicly and where additional sites and links, or other interesting bookmarks, can be added to the collection for individual use or shared with others for example, resources on essay planning/writing. 
The Academic Skills Team was seeking to provide access to recommended learning development resources within a web environment. Rather than use a static webpage to which only the tutors contributed and students passively consumed, a more dynamic and interactive approach was preferred. Another consideration was the University of Huddersfield's devolved (as opposed to centralised) learning development provision, with Academic Skills Tutors (ASTs) based within individual Schools and Campuses, each having their own subject specific needs. Del.icio.us provided a suitable platform for tailoring resources to particular subject disciplines, whilst retaining the benefits of network connectivity to other subject areas.

Over the summer of 2007, the ASTs tagged (bookmarked) web pages using del.icio.us. The bookmarks were labelled with significant words (tag) and contained explanatory commentary and guidance to aid students. Consequently, each tutor has developed their own del.icio.us list of annotated and tagged resources, which can be interlinked with lists from other tutors; these became live in September 2007. The use of del.icio.us is actively promoted to staff and students during induction sessions, through publicity materials (including the team website and VLE) and is integrated within individual student tutorials, email communications and relevant group sessions.

Following the introduction of del.icio.us by the Academic Skills Team, a small scale evaluation study was undertaken by the AST at the Oldham Campus. A naturalistic paradigm of qualitative data collection formed the basis of the study, since it provided a rich insight into the students' experience. In order to establish the validity of the data, the scope of the study involved a range of methods for example, a focus group, observations and the monitoring of del.icio.us link usage.

The aim of the study was to encourage students to investigate and use the tag collection, created by the AST at the Oldham Campus (Figure 1). Students were introduced to the social bookmark tool del.icio.us by the AST; the students were encouraged to register with the service, personalise their own delicious page while engaging and constructing new tags. An email message was sent to the students which contained a hyperlink to the AST's delicious page. A focus group was formed since it was felt that it presented a comprehensive system of participative research to discuss, influence and share aspects of the resource. In addition a number of full time students agreed to be observed individually as they interacted with the resource. Furthermore, since each tag on the AST's del.icio.us 
page illustrates to what degree someone (a registered user) has considered a tag useful, the number of occurrences provided an indication of the tag's use.

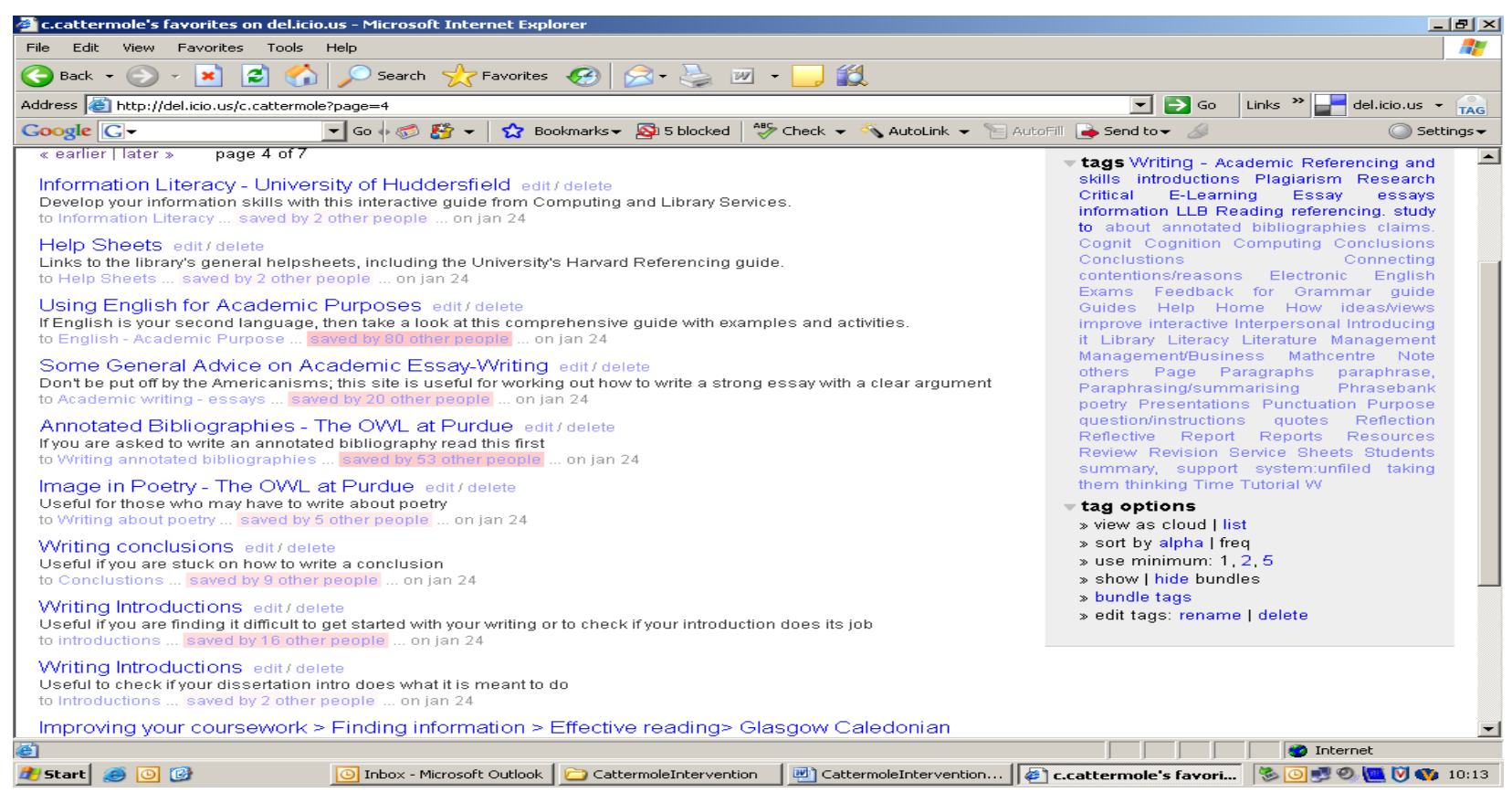

\section{Figure 1. A screen shot of del.icio.us page.}

The response from the focus group regarding social bookmarking was a positive one. $A$ particular comment revealed that '...using delicious tags helped me to become much more organised.' Further elicited from the focus group was that the '...time saved is sometimes used looking at other 'interesting' things'. However, the observations generated insignificant data, since each student explored the tags purposefully and with confidence. Students generally employed specific tags to a subject rather than investigating other tags that were perhaps related.

By March 2008, 67 tags on the Oldham Campus tutor's page were available offering URL links to information ranging from 'academic essay writing' to 'Oxford law'. The extent to which the tags had been bookmarked ranged quite significantly; the most common 'English for academic purposes' had 80 users bookmark the tag, followed by 'punctuation' with 64 users' tagging it. However, what was significant was that a number of tags had not been bookmarked at all. The indices used by del.icio.us to record the frequency of bookmarking, in some part, form the evaluation of the perceived worth by users of the tags. This raised concerns in respect of whether students understood how to use del.icio.us, whether students were aware of the resource regardless of the promotional 
activities and whether the tag categorisation was ambiguous since different tags can emerge for the same concept. However, the ease with which users can register with del.icio.us is straightforward and the creation of individual pages and deploying tags is easy. Therefore, in terms of individual and educational use, social bookmarks have the potential to bring together users with common interests, hence having some time-saving value.

\section{Wikis: fostering collaboration}

Wikis are an asynchronous communication tool, allowing users to create multimedia content collaboratively, with Wikipedia (http://www.wikipedia.com) being the most famous example. Since 2007, the AST in the School of Art, Design and Architecture has explored the use of wikis to encourage effective team working, collaborative research and writing amongst first year textile craft undergraduates. The textile craft students were engaged in an Academic Skills module, involving substantial teamwork to research and produce a group presentation about a textile artist and reflect upon this experience. Wikis were introduced in response to a prevalent theme within previous student reflections: a recognised need by students for more effective organisation and communication. Students were often in different course groups, having different timetables, and found it difficult to meet as a team. As previously demonstrated, students are actively engaged with social software for everyday communication; however, the question was whether this could be extended to encompass and promote social learning and collaboration as a team.

Rather than use the wiki provided by our institutional Blackboard VLE, which at the time lacked the visual capabilities that would appeal to art and design students and their research interests, it was decided to use the Web 2.0 PBwiki (http://pbwiki.com/), using the VLE as the gateway to this application. A PBwiki was created by the tutor for each team (42 students, 11 teams); students can view other team wikis but can only edit their own with an allocated password. In addition to the team password, students also provide their own username, which is displayed if they edit the wiki, allowing a tutor to note individual contributions. Each wiki page also has access to an archival history, allowing a tutor to track progressive development of the wiki and students to access and revert to earlier versions of a page, if they so wish. From past experience, when wikis were first suggested 
as an option within the module with unsurprisingly very little uptake, it was felt important to integrate the wiki into the module delivery and assessment (see Table 1).

Table 1. Relationship between module and use of the wiki.

\begin{tabular}{|c|c|}
\hline Example Module Sessions & Wiki Activity \\
\hline $\begin{array}{l}\text { Introduction to module and 'Getting to know } \\
\text { your team' }\end{array}$ & $\begin{array}{l}\text { Writing individual profiles on wiki front page, } \\
\text { team photographs and what they hope to } \\
\text { achieve in the module; team visit to art } \\
\text { exhibition and writing collaborative } \\
\text { exhibition review (see Figures } 2 \text { and } 3 \text { ) }\end{array}$ \\
\hline Team work and team building & $\begin{array}{l}\text { Establishing team ground rules, area for } \\
\text { team meeting notes and actions }\end{array}$ \\
\hline Time management and project planning & Developing team project plan \\
\hline Academic research & $\begin{array}{l}\text { Space to collate research findings for team } \\
\text { project }\end{array}$ \\
\hline Harvard referencing & Collaborative creation of reference list \\
\hline Oral presentations & $\begin{array}{l}\text { PowerPoint slides can be uploaded onto the } \\
\text { wiki for team collaboration and editing }\end{array}$ \\
\hline Reflective writing & $\begin{array}{l}\text { Area on the wiki with questions to prompt } \\
\text { reflection on teamwork project and process }\end{array}$ \\
\hline
\end{tabular}

Although structured and integrated, students were encouraged to customise their wiki to 'make it their own', changing 'skins', incorporating different colour schemes, images and additional wiki pages (see Figures 2 and 3 for example wiki pages). 
Figure 2. Wiki front page.

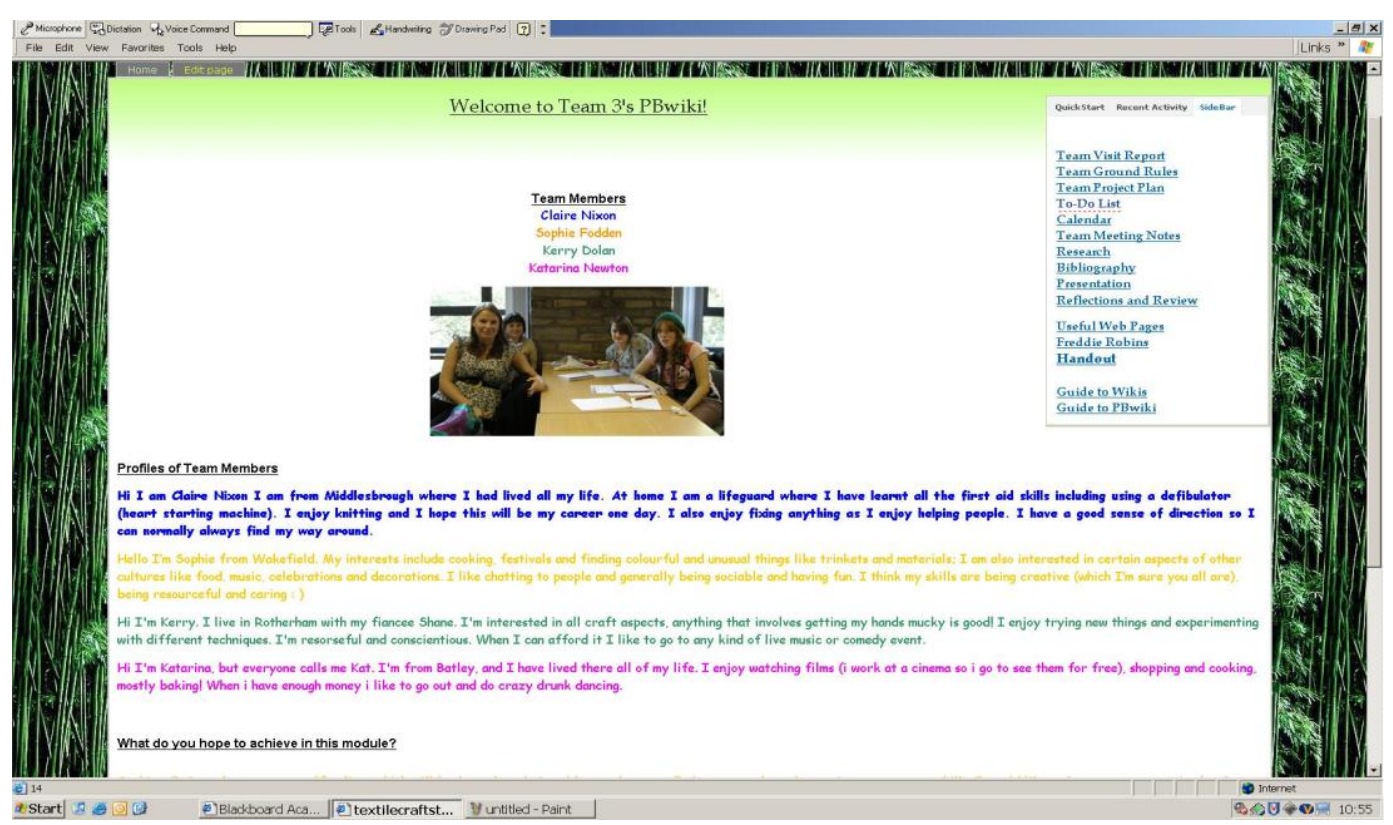

Figure 3. Team building through collaborative exhibition review.

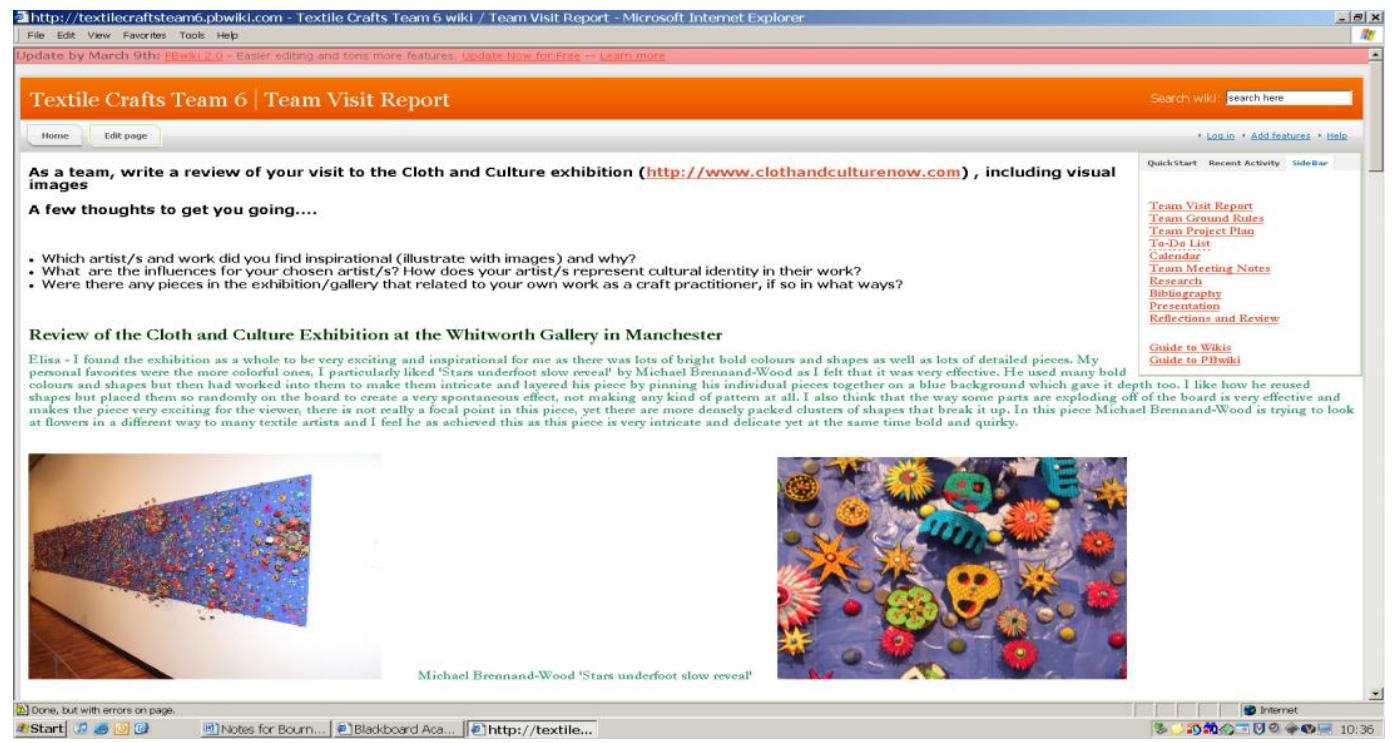

The wiki is not directly assessed, primarily due to the content being held by an external party, yet it is integrated. As part of their reflective assignment, students are asked to evaluate the role of the wiki in supporting their teamwork and, from this academic year, include relevant screenshots to evidence their teamwork process.

Qualitative analysis of these student reflections and a feedback questionnaire identified both positive and negative aspects. Students found the wiki a valuable space for storing and sharing their research and exchanging ideas; this peer learning also appeared particularly valuable in facilitating a greater understanding of referencing techniques: 
...great way to store information especially the Harvard referencing I had to make for all the images and information used.

The main reason we worked well together was we used the Wiki to communicate our research.

Providing an organisational framework for their teamwork was another important aspect:

It gave us a structure to help plan and organise ways of approaching the task.

There is no doubt that the wiki was a big factor in our good organisational skills for this project.

We kept referring back to the team plan. This helped us structure our meetings and kept us on target.

Students also found that they worked more efficiently as a team, discouraging duplication of effort:

...stopped us looking at the same websites more than once.

Moreover, as the students were using the wiki in the first term of their first year undergraduate course, they enjoyed viewing each other's wikis to learn about and learn from their peers, aiding cohort integration and transition:

... a good idea to get us started and introduced to each other. Helped you learn more about your class mates.

It was interesting to look at [other] groups' work.

However, despite these successes, due to limited internet access, some students found it difficult to contribute regularly. This may also be due to the nature of the Textile Craft course, with its studio bias, providing less opportunity and facilities for computer access. Other students, despite recognising the potential of the wiki and the tutor emphasising that 
is was a supplementary (not replacement) tool, still preferred the immediacy of email, text or face-to-face communication:

...found PBwiki to be a little more complicated and meeting up was much more appropriate and constructive.

Furthermore, the asynchronous nature of the wiki may have discouraged participation amongst some, allowing only one student at one time to edit and contribute. The potential of additional synchronous tools, such as Etherpad (http://etherpad.com/), is currently being explored to allow a more dynamic interaction in 'real time'. This year, one team of students began to address this issue themselves by creating their own Facebook group with a link from the wiki and vice versa; the wiki was used as the shared research repository and the Facebook group for quicker communication (arranging team meetings etc.). Other issues include the need for equal participation (a perennial issue in many team work projects) and learnability; as previous research has shown (Currant, et. al., 2008. Although students may regularly use social software, a new tool (particularly when used in a different learning context) may present a learning curve, requiring more training than might be expected.

Overall, the wiki has been found valuable for tutors in making the teamwork process more visible, allowing monitoring of student progress and early identification of any participation issues. Similarly, as a repository, the students also have a record of their collaborative research and teamwork process, which can form the basis for their reflection and identification of learning. However, a wiki cannot create a successful team and it is not a panacea for all. As one successful team noted, its role is to 'consolidate'.

\section{Social networking: creating learning communities}

Social networking software enables groups of people with shared interests to collaborate and share electronic data in many forms. Ning (http://www.ning.com) is a free site that allows the creation of a network easily and quickly. The network can be either public (anyone with access to the web can view and join the network) or private (members are by invitation only and the site is password protected) and the administrator can edit content and prohibit members as necessary and appropriate. Since September 2008 the Business School Academic Skills Tutors (BSASTs) at the University of Huddersfield have been 
exploring ways in which Ning can be used to create learning communities. This exploration has involved using Ning to create a student-led learning community based on the issue of referencing and plagiarism and additionally to provide a collaborative writing tool that could be utilised in a structured manner during taught sessions.

The BSAST's first use of social networking software has been as part of a wider project that seeks to prevent plagiarism by using technology to up-skill the student and was inspired by the University of Bradford's successful use of Ning to create their social network Develop Me! (University of Bradford, 2008). The project's aim is to create a variety of technological approaches to the teaching and learning of the principles of Harvard referencing, addressing the individual needs of all Business School students with diverse learning styles. A range of technologies have been utilised both in formal teaching and informal learning situations including Blackboard, voting pads and a social network entitled Academic Matters, hosted on Ning (Figure 4).

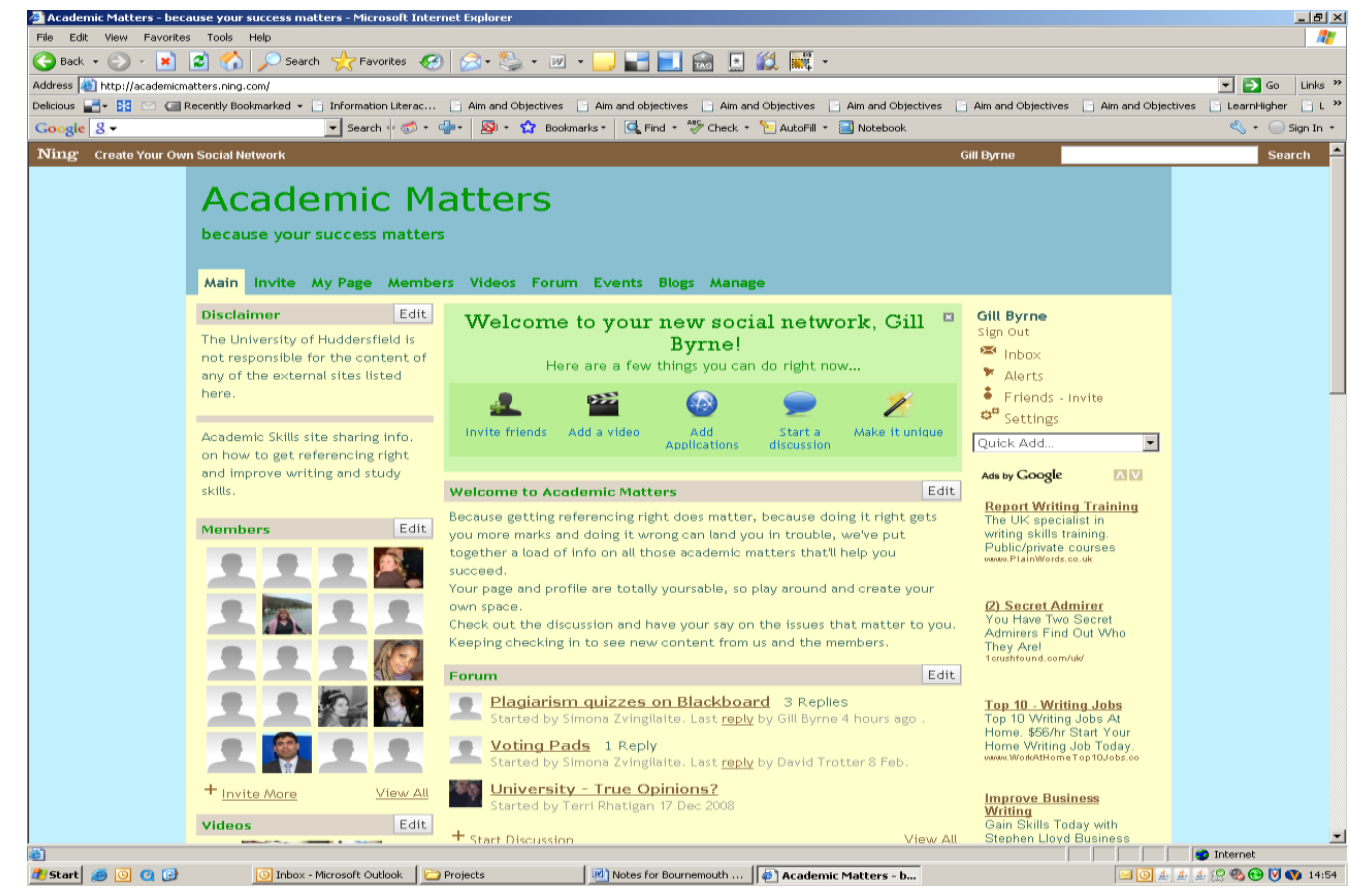

Figure 4. Academic Matters Ning.

Academic Matters provides links to information about referencing, recent contemporary examples of plagiarism in music and other media, videos and discussion forums. It was created to provide an alternative, informal, student space in which learners could share their ideas and concerns about this issue. As such, it highlights for students that plagiarism is not only a concern for universities but also one for industry and popular culture. In this 
way it was hoped that the subject would be made more accessible for students and that Academic Matters would engender a student-led social learning community.

It was decided, in this first use of the technology, that the network be private to lessen the burden of monitoring the site for inappropriate user-generated content. All of the Business School students, some 4000, were invited during the first few weeks in term one. This was a lengthy and time consuming activity that resulted in a delay between students being told about the network during induction and them receiving their invitation email. Take up and activity was very low; with 54 students signing up. A second invitation created a further 25 members. Although an invitation-only approach would appear to be the safest option and one that protects both students and institutions, it is not without its issues, one of which is that where a site remains private members are invited via a mass, software-generated email. As a consequence the invitation email is in danger of becoming 'lost' amongst the many others that web users regularly receive in the form of spam. Further, the recipient is unable to view and assess the network prior to registration. This has been identified as a possible barrier to engagement; however, making a site public is also problematic, as the possibility of inappropriate participation makes rigorous monitoring of the site advisable (Currant, 2009). Another issue with the invitation-only approach is that tutors, more often than not, only have access to university email addresses and many students choose to use personal email, rarely checking their university accounts.

In response to the lower than expected participation level it was decided to make the site more prominent by embedding it within the university's VLE, blackboard, but to make it public so that no invitation email was necessary. In this way it was hoped that students would be more likely to view the site and participate. As previously discussed, although the evidence is clear that students are readily utilising Web 2.0 technology to organise their social lives, it remains unclear whether they can or indeed want to make the transition from using these tools for entertainment to engaging with them within an educational context (Hoare, 2007; Minocha, 2009). The evidence seems to suggest a confused and complex picture as although students appear to use Web 2.0 informally to discuss their courses (Ipsos MORI on behalf of JISC, 2007; JISC, 2007), they are not necessarily comfortable doing so within a formal context. 'As one lecturer recently found out, it is easier to join with the herd and discuss this week's coursework online within Facebook ...than to try and get the students to move across to the institutional VLE' (Anderson, 2007: 21). However, following students into their online space is not always welcomed either (Hoare, 2007). In 
an effort to bridge this gap between a standardised approach that can be afforded by using a VLE and the students' desire for privacy and control over their own online space, the decision was made for BSASTs to minimise their own presence on the site but to employ a student ambassador to encourage and manage participation. This resulted in a slight increase in student participation and membership now stands at 92. Literature would suggest that social networks need a critical mass in order to be successful and to generate their own momentum (Minocha, 2009). Barriers to reaching this point can involve privacy issues, a reluctance to use new tools and a blurring of personal and academic boundaries (Minocha, 2009).

The use of Academic Matters is still in its infancy and it is hoped that the decision to make the site public will positively impact on participation as there will be no delay in the second year of its use between new students hearing about the tool during induction and their being able to access it. Future research will include examining usage statistics generated by Google Analytics (http://www.google.com/analytics/en-GB/) and student evaluation feedback. The latter, in particular, will hopefully provide insight into the site's usability, its perceived value and students' support needs in its use.

In contrast to this, the BSASTs explored a more structured use of Ning during a Bridging Course, which is traditionally run during the second week in September. This is a four day intensive course which covers reading, writing, research and presentation skills and is attended by Foundation and HND students transferring on to degree courses. Here the Ning (Figure 5) was utilised to facilitate collaborative writing. The site was divided into sections that represented the different chapters of a dissertation and the students were set the task of writing a mini-dissertation on the topic of the conventions of academic writing. The site was again private but was introduced to the students, along with explicit training in its use and then utilised extensively by both staff and students during taught sessions. The students were therefore supported in their use of the technology. This formal use of the tool proved successful and students were positive about the technology in their evaluation feedback:

Easy to learn with technology used.

It was good and different trying out the new technology; it broke the day up well. 
It was attracting my attention to keep working and not to be bored.

\section{Figure 5. Bridging Course Ning.}
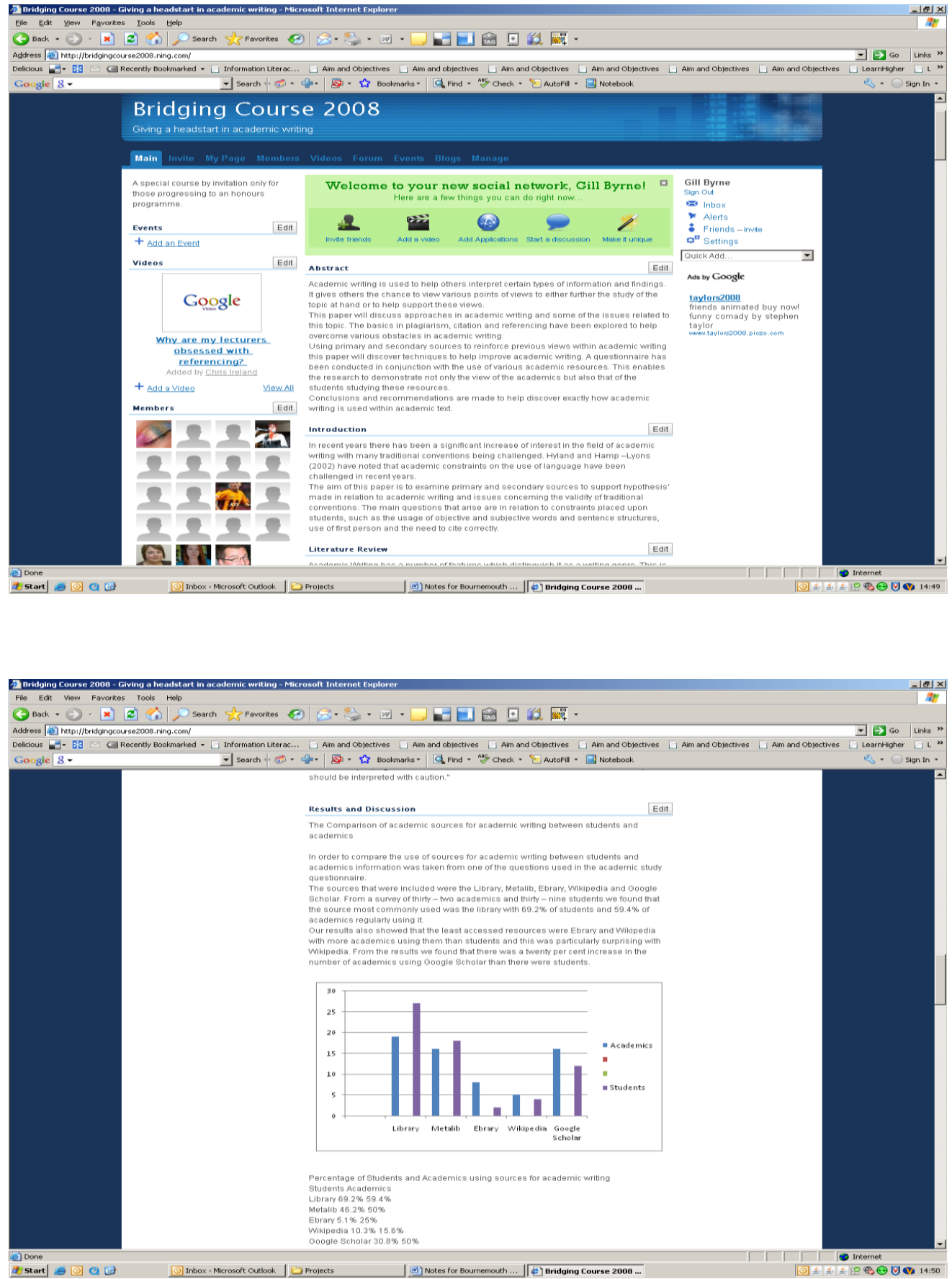

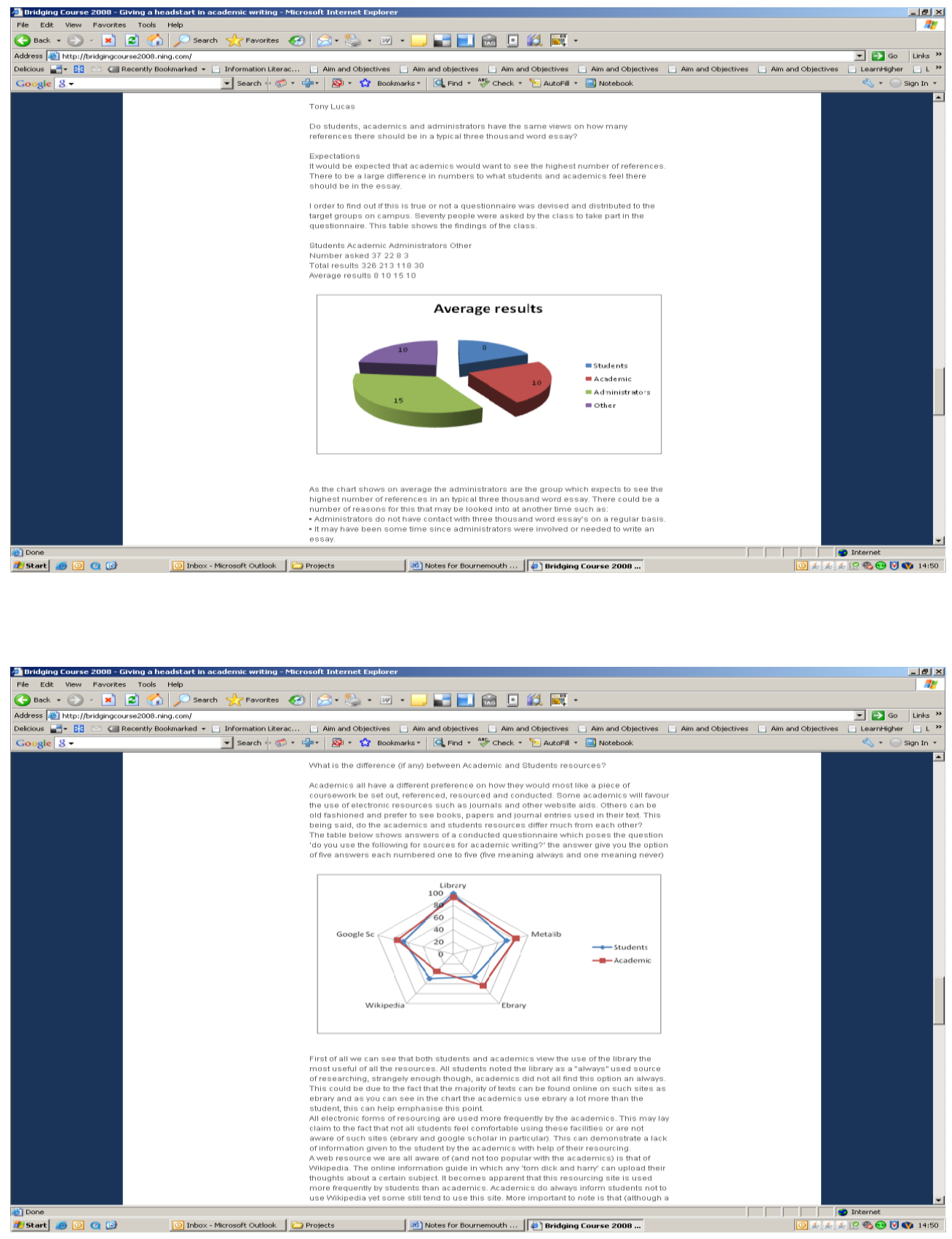

It would seem that when comparing the two approaches, structured, embedded and nonstructured and non-embedded, that the BSASTs experiences of the use of Web 2.0 technology concurs with literature that suggests that the shift from entertainment to education is not always an easy one and that familiarity with the technology cannot be assumed (Minocha, 2009; Currant, et. al., 2008). In particular it would seem that the use of web 2.0 technology is more successful where it is explicitly supported and linked to assessment. 


\section{Conclusion}

This paper has demonstrated how three Web 2.0 tools are being explored in supporting social learning within Higher Education. With an increase in both independent and collaborative learning, the use of technology in learning and the way information is constructed and consumed, social software affords an opportunity for users to locate, assemble and create a range of information suitable to their individual needs and, more significantly, enables them to share this with others. However, Web 2.0 technology use is still relatively new within educational domains, with little data available to define the true evaluative expediency. Although there appears to be a clear potential for such tools in contributing and sharing resources, facilitating teamwork collaboration and communication, and creating learning communities, their full realisation still remains in transition. Despite students using Web 2.0 tools, such as Facebook, for social purposes, it cannot be assumed that all students are able or even willing to engage in this same way within an educational context. The experience and evaluation to date suggests that the technology is most positively received when appropriately integrated and embedded within teaching, ideally within relevant modules and linked to assessment. In so doing, students may begin to recognise the value for themselves and their own educational development within a collaborative learning community.

\section{References}

Alexander, B. (2006) 'Web 2.0: A new wave of innovation for teaching and learning?', Educause Review 41(2) pp 32-44.

Anderson, P. (2007) 'What is web 2.0? Ideas, technologies and Implications for education', JISC Technology and Standards Watch, February. ONLINE:

http://www.jisc.ac.uk/publications/publications/twweb2.aspx [Accessed: 4 November 2008].

Berners-Lee, T. (1999) Weaving the web: the past, present and future of the World Wide Web by its inventor. London : Orion Business. 
Boulos, M.N.K. and Wheeler, S. (2007) 'The emerging web 2.0 social software: an enabling suite of sociable technologies in health and health care education', Health Information and Libraries Journal 24(1) pp 2-23.

Currant, B. (2009) 'Support Me! Develop me! Enhancing the student experience and engaging with users before they arrive', LearnHigher website launch. University of Leeds, Leesd 23 January.

Currant, N., Currant, B., Whitfield, R. and Hartley, P. (2008) Defining 'Generation Y': towards a new typology of digital learners. ONLINE: http://www.elp.ac.uk/downloads/Defining \%20Generation\%20Y\%20Bradford.pdf (Accessed: 4 November 2008).

Dotsika, F. and Patrick, K. (2006) 'Towards the new generation of web knowledge', The Journal of Information and Knowledge Management Systems 36(4) pp 406-422.

Hoare, S. (2007) 'Students tell universities: get out of MySpace!' The Guardian, 5 November. ONLINE: http:www.guardian.co.uk/education/2007/nov/05/link.students (Accessed: 28 January 2009).

Ipsos MORI on behalf of JISC (2007) Great expectations of ICT: how higher education institutions are measuring up. ONLINE:

http://www.jisc.ac.uk/publications/documents/studentexpectations.aspx (Accessed: 20 February 2009).

JISC (2007) Secure personal institutional and inter-institutional repository. ONLINE: http://www.jisc.ac.uk/media/documents/programmes/digitalrepositories/spiresurvey. pdf (Accessed: 26 July 2008).

JISC (2008) Great expectations of ICT: how HE institutions are measuring up. Press release, 12 June. ONLINE:

http://www.jisc.ac.uk/news/stories/2008/06/greatexpectations.aspx (Accessed: 28 January 2009). 
Mason, R. and Rennie, F. (2008) E-learning and social networking handbook: resources for higher education. Oxford: Routledge Ltd.

Minocha, S. (2009) A study on the effective use of social software by further and higher education in the UK to support student learning and engagement (final report). UK: JISC. ONLINE: http://kn.open.ac.uk/public/getfile.cfm?documentfileid=14865 (Accessed: 2 December 2009).

Prensky, M. (2001) 'Digital Natives, digital immigrants', On the Horizon, MCB University Press 9(5) pp 1-6.

University of Bradford (2008) Develop Me! ONLINE: http://developme.ning.com/ (Accessed: 18 February 2009).

\section{Author details}

Amanda Tinker, Gill Byrne and Christine Cattermole are Academic Skills Tutors in the Schools of Art, Design and Architecture; Business; and Oldham Campus at the University of Huddersfield which has a devolved model of learning development provision:

Dr Amanda Tinker has a degree in English Language and Linguistics and MSc. in Library and Information Science. She is Learning Development Team Leader within her School, a chartered librarian and Fellow of the Higher Education Academy. She completed her $\mathrm{PhD}$ in information retrieval, classification and library systems in 2006. Since 2002, she has focused her teaching and research interests within the field of learning development.

Gill Byrne has a degree in English Studies and an MSc in Multimedia and Education. She has worked in education for 12 years, beginning by teaching English Literature, English Language and Study Skills on an Access to HE course before moving into Higher Education and learner development 3 years ago. She is a qualified dyslexia support tutor. 
Christine Cattermole is the Academic Skills Tutor at University Campus Oldham, a campus of the University Oldham. She has a degree in Business and Law, Masters in Business Management, a PGCE and Dyslexia Support and she is currently completing an MSc in Multimedia and E-Learning. Her work in education has been teaching AS and A level law, Business Studies and ICT, and Business and IT, and Law for Access to Higher Education before moving into learning development. 